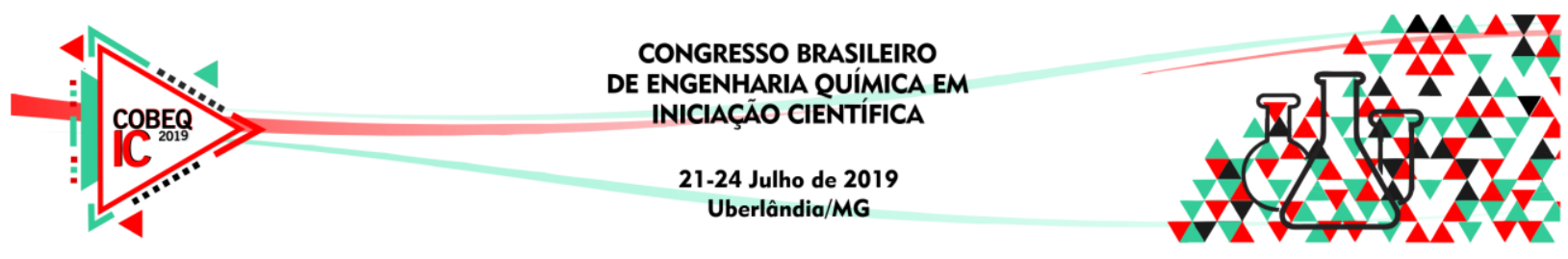

\title{
SÍNTESE DE LIPÍDEOS ESTRUTURADOS EMPREGANDO LIPASE DE Rhizopus oryzae IMOBILIZADA EM PÓ DE SABUGO DE MILHO.
}

\author{
V. G. BATISTA ${ }^{1}$, B.M.SILVA ${ }^{1}$, J.P.M.GALAN ${ }^{2}$, R. MONTI ${ }^{3}$, A.V.PAULA ${ }^{1}$ \\ ${ }^{1}$ Universidade Estadual Paulista, Departamento de Bioprocessos e Biotecnologia \\ ${ }^{2}$ Universidad de Antioquia, Escuela de Nutrición e Dietética \\ ${ }^{3}$ Universidade Estadual Paulista, Departamento de Alimentos e Nutrição \\ E-mail para contato: vinicius.guerso@unesp.br
}

\begin{abstract}
RESUMO - A necessidade de maior qualidade de vida tem levado a população a buscar por alimentos nutracêuticos, tais como os lipídeos estruturados do tipo MLM, triglicerídeos com ácidos graxos de cadeia média (M) nas posições sn-1 e sn-3 e longa (L) na posição sn-2 e que por este motivo apresentam menor valor calórico que os óleos tradicionais. Por isso o objetivo desse trabalho foi sintetizar lipídeos estruturados do tipo MLM através da acidólise enzimática do óleo de semente de uva empregando lipase de Rhizopus oryzae imobilizada em pó de sabugo de milho. Para isso, tal material foi tratado termicamente em autoclave, seguido de tratamento básico com $\mathrm{NaOH}$. Posteriormente o pó de sabugo de milho foi submetido ao processo de ativação e funcionalização com glutaraldeído. Após imobilização o derivado obtido foi submetido à acidólise enzimática do óleo de semente de uva, com meio composto por óleo e ácido cáprico (C10) na razão molar de $1: 3$, durante $24 \mathrm{~h}$ a $45^{\circ} \mathrm{C}$. Reusos do derivado imobilizado foram realizados para verificar a estabilidade operacional. O derivado apresentou 62,00 $\pm 4,45 \mathrm{U} / \mathrm{g}$, e incorporou $54,00 \%$ em mol de $\mathrm{C} 10$. Foram realizados 5 reusos, promovendo incorporação média de 38,80 \%mol. Tais resultados mostraram relevante capacidade do derivado obtido em sintetizar lipídeos estruturados do tipo MLM, sendo promissores na área de bioprocessos e enzimologia.
\end{abstract}

\section{INTRODUÇÃO}

As exigências do consumidor por produtos mais saudáveis, associadas às novas descobertas científicas sobre os efeitos benéficos que os alimentos podem introduzir à saúde humana, motivou a busca por processos adequados que fossem capazes de produzir estes alimentos específicos. Neste sentido, destacam-se os lipídeos estruturados que são óleos e gorduras com propriedades nutracêuticas básicas que, além de nutritivos, apresentam efeitos metabólicos e fisiológicos interessantes para a prevenção e tratamento de doenças (SILVA et al., 2009).

Dentre estes lipídeos, pode-se citar os triglicerídeos do tipo MLM, que possuem ácidos graxos de cadeia média (M), nas posições $s n-1$ e $s n-3$, e de cadeia longa (L), na posição interna $s n-2$ da molécula de triglicerídeo. Há um grande interesse na produção deste triglicerídeo por conta do seu baixo índice calórico e facilidade na metabolização, sendo então 


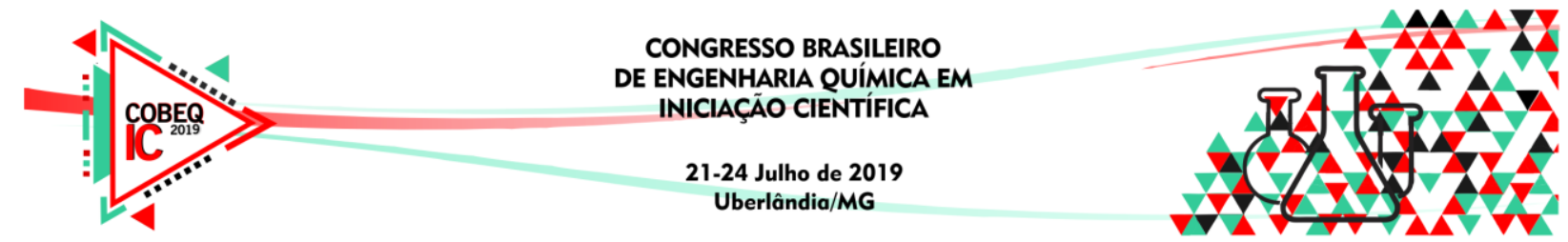

indicado para pessoas com deficiências metabólicas. Os triglicerídeos MLM podem ser sintetizados por via química ou enzimática (NUNES et al., 2012).

A síntese enzimática destes compostos é realizada pelas lipases (glicerol éster hidrolases - E.C. 3.1.1.3), biocatalisadores que atuam na molécula do triacilglicerol. Estas enzimas podem catalisar diversos tipos de reações a depender do meio ao qual estão inseridas, podendo ser aquoso ou orgânico (NARWAL; GUPTA, 2013). Para essas enzimas serem utilizadas e aplicadas industrialmente, é necessário ter o conhecimento da especificidade da lipase e também que, se possível, estejam imobilizadas, pois dessa maneira pode-se reutilizálas no bioprocesso de interesse (CASTRO et al., 2004). Para isso é necessário o emprego de um suporte que possibilite a interação com a enzima e se realize o processo de imobilização. Dentre os suportes, destaca-se o sabugo de milho.

Este material é um resíduo agroindustrial oriundo da produção de milho e seu uso fica restrito às atividades secundárias como aditivos em ração animal, cobertura do solo, filtro, enchimento, fonte de carvão, entre outros, não sendo explorado em todo o seu potencial. Logo, a utilização do pó de sabugo de milho para imobilização de enzimas agrega valor a este resíduo, uma vez que o mesmo é subutilizado no agronegócio (BRÍGIDA, 2010). Este material é constituído principalmente de celulose, hemicelulose e lignina. Esta grande porcentagem de celulose presente no sabugo o torna viável para utilização em imobilização de enzimas, uma vez que a superfície da estrutura de celulose possui grupos hidroxilas livres, o que permite que estes grupos sofram modificações e passem por processos de ativação, para que assim possa haver ligação covalente, por exemplo, entre a enzima e o suporte funcionalizado (ASHOUR et al., 2013).

\section{OBJETIVO}

O objetivo do presente trabalho foi avaliar a síntese enzimática de lipídeos estruturados do tipo MLM, empregando-se lipase imobilizada em pó de sabugo de milho, por meio da acidólise do óleo de semente de uva e ácido cáprico (C10) .

\section{MATERIAL E MÉTODOS}

\subsection{Enzima}

Os experimentos foram efetuados empregando preparação de lipase de Rhizopus oryzae, de grau alimentício (Prozyn, São Paulo).

\subsection{Reagentes}

Como matéria prima, foram utilizados o óleo de semente de uva (Distriol, São Paulo) e ácido cáprico (C10) (Sigma Aldrich, Alemanha). O suporte utilizado foi o pó de sabugo de milho adquirido no mercado local. Outros reagentes utilizados foram: acetona P.A. (Neon, São Paulo), azeite de oliva comercial (Carbonell, Espanha), etanol absoluto (Neon, São Paulo), hexano (Neon, São Paulo). Os demais reagentes foram de grau analítico. 


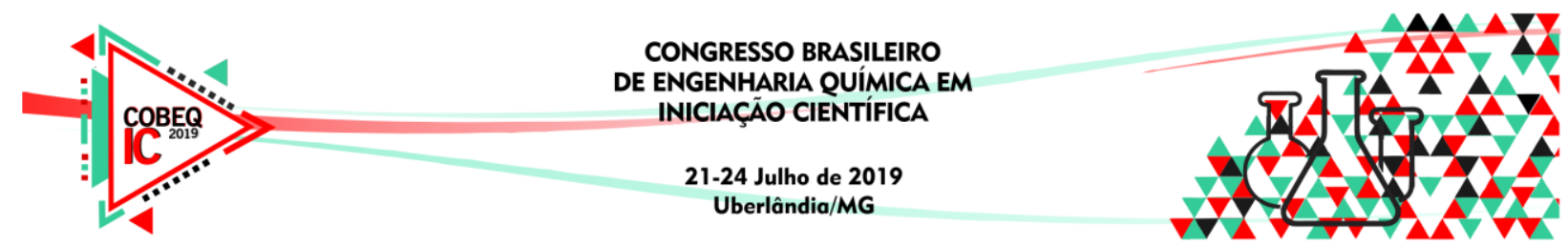

\subsection{Procedimento Experimental}

Imobilização da Lipase de Rhizopus oryzae em pó de sabugo de milho por ligação covalente: $\mathrm{O}$ pó de sabugo de milho foi lavado abundantemente com água, tratado com álcool $70 \%$ e submetido à descompressão térmica, com auxilio de uma autoclave, visando expandir os materiais lignocelulósicos e aumentar a área de superfície. Posteriormente o pó de sabugo de milho foi mantido em agitação suave $(140 \mathrm{rpm})$ por 24 horas em $\mathrm{NaOH}(2 \mathrm{M})$ para quebra e remoção da lignina, lavado com água em abundância e filtrado a vácuo. Para obtenção do suporte ativado com glutaraldeído foi empregada metodologia descrita por (BASSAN et al., 2016).

Determinação da atividade hidrolítica: A atividade hidrolítica foi determinada pelo método de hidrólise do azeite de oliva segundo Paula (2012).

Reação de Acidólise visando a síntese de lipídeos estruturados: A biotransformação do óleo de semente de uva foi conduzida em reator de tanque agitado operando em batelada, sendo o meio composto por óleo de semente de uva e ácido cáprico na razão molar de 1:3 (óleo:ácido) a $45^{\circ} \mathrm{C}$ e por 24 horas.

Análise da estabilidade operacional do derivado imobilizado: Foram realizados reusos do derivado imobilizado obtido visando verificar a estabilidade operacional do mesmo. Para isso após cada batelada realizada a lipase imobilizada foi recuperada, lavada abundantemente com hexano e empregada novamente em um novo meio reacional nas mesmas condições descritas anteriormente.

Determinação do Grau de Incorporação do ácido graxo de cadeia média: O grau de incorporação (GI) foi calculado de acordo com a equação 1 (CASAS-GODOY et al., 2013), na qual MFA é o número de mols de ácidos graxos de cadeia média (C10:0) no triglicerídeo e MT é o número de mols totais de ácidos graxos no triglicerídeo.

$$
G I(\%)=\frac{M F A}{M T} \cdot 100
$$

\section{RESULTADOS E DISCUSSÃO}

\subsection{Imobilização da Lipase em pó de sabugo de milho e aplicação em reação de acidólise.}

Após a imobilização da lipase de Rhizopus oryzae em pó de sabugo de milho, como descrito em 3.3, o derivado obtido foi submetido à dosagem da atividade hidrolítica. Desta maneira, o resultado foi de $62,00 \pm 4,45 \mathrm{U} / \mathrm{g}$. Tal derivado foi empregado na reação de acidólise do óleo de semente de uva, conforme descrito em 3.3. A figura 1 a seguir apresenta o biorreator bem como o meio reacional empregado na reação. 


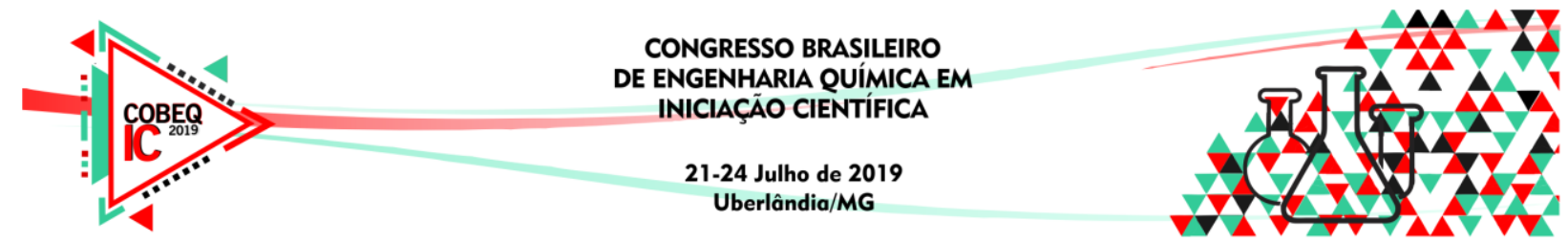

Figura 1 - Reação de acidólise do óleo de semente de uva em reator de tanque agitado operando em batelada.

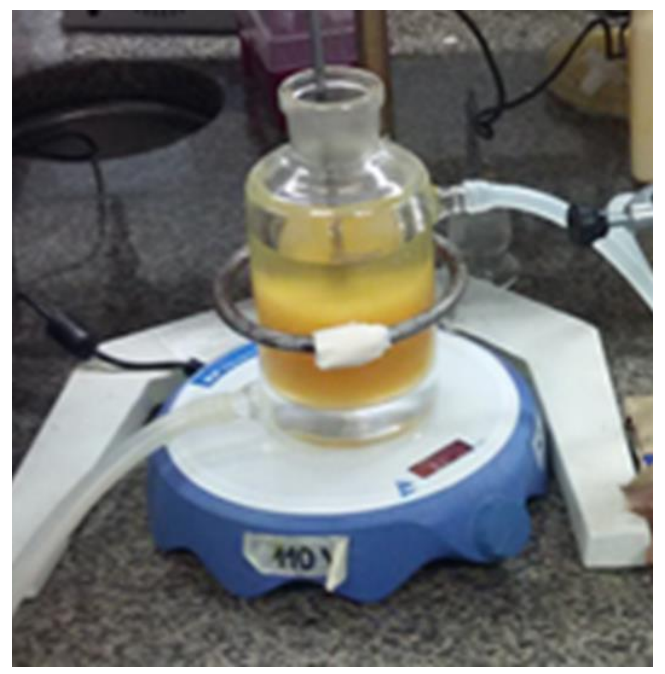

A Tabela 1 a seguir apresenta o grau de incorporação (GI) do ácido graxo de interesse (C10), obtido na reação empregando-se lipase de Rhizopus oryzae imobilizada em pó de sabugo de milho.

Tabela 1 - Grau de Incorporação do ácido cáprico (C10) no lipídeo sintetizado por meio da reação de acidólise do óleo de semente de uva, empregando-se lipase imobilizada em pó de sabugo de milho.

\begin{tabular}{|c|c|c|c|}
\hline Ácido Graxo & $\begin{array}{c}\text { Concentração } \\
(\boldsymbol{\%})\end{array}$ & $\boldsymbol{\%}$ molar & $\begin{array}{c}\text { GI } \\
(\boldsymbol{\%} \text { mol })\end{array}$ \\
\hline \hline C10: 0 & 42,07 & 0,24 & 54,00 \\
\hline C16:0 & 5,48 & 0,02 & \\
\hline C18:0 & 1,60 & 0,01 & \\
\hline C18:1 & 13,60 & 0,05 & \\
\hline C18:2 & 33,76 & 0,12 & \\
\hline C18:3 & 3,49 & 0,01 & \\
\hline Total & 100,00 & 0,45 & \\
\hline
\end{tabular}

Como se pode observar na Tabela 1 , o GI obtido foi de 54,00 \%, valor muito satisfatório uma vez que o máximo que se pode obter é $66,66 \%$ devido a especificidade da enzima, que hidrolisa e esterifica majoritariamente as posições sn-1 e sn-3 do triglicerídeo. Segundo Nunes e seus colaboradores (2011), que realizaram acidólise enzimática do azeite de oliva, empregando a mesma lipase utilizada neste trabalho, porém imobilizada em Eupergit ${ }^{\circ}$, para incorporação do ácido cáprico (C10), obtiveram valor de GI de 34,80 \% mol. Tal 


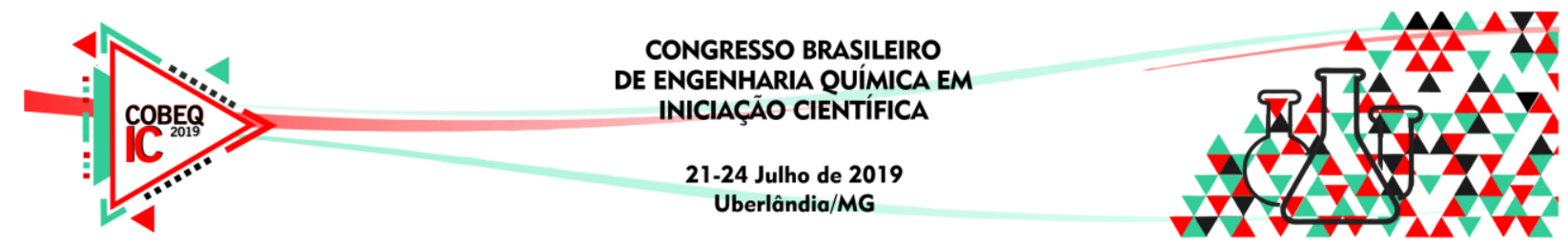

resultado mostra a grande relevância no emprego de lipase imobilizada em pó de sabugo de milho na síntese de lipídeos estruturados, uma vez que os resultados obtidos neste trabalho foram superiores ao relatado pela literatura. Este resultado pode ser explicado pela diferença de substratos e os suportes empregados. Tais fatores são primordiais e determinantes para atuação do biocatalisador, uma vez que diferentes substratos podem propiciar diferentes afinidades enzima-substrato, e já o suporte, bem como o processo de imobilização, tem por consequências diversos efeitos inerentes ao processo, tais como efeitos estereoquímicos e de transferência de massa, que influenciam diretamente na biocatálise desejada (CABRAL; AIRES-BARROS; GAMA, 2003).

\subsection{Estabilidade operacional do derivado imobilizado obtido.}

Conforme descrito em 3.3, foram realizados reusos da lipase imobilizada em pó de sabugo de milho e os resultados obtidos podem sem visualizados na figura 2.

Figura 2 - Reusos da lipase de Rhizopus oryzae imobilizada em pó de sabugo de milho

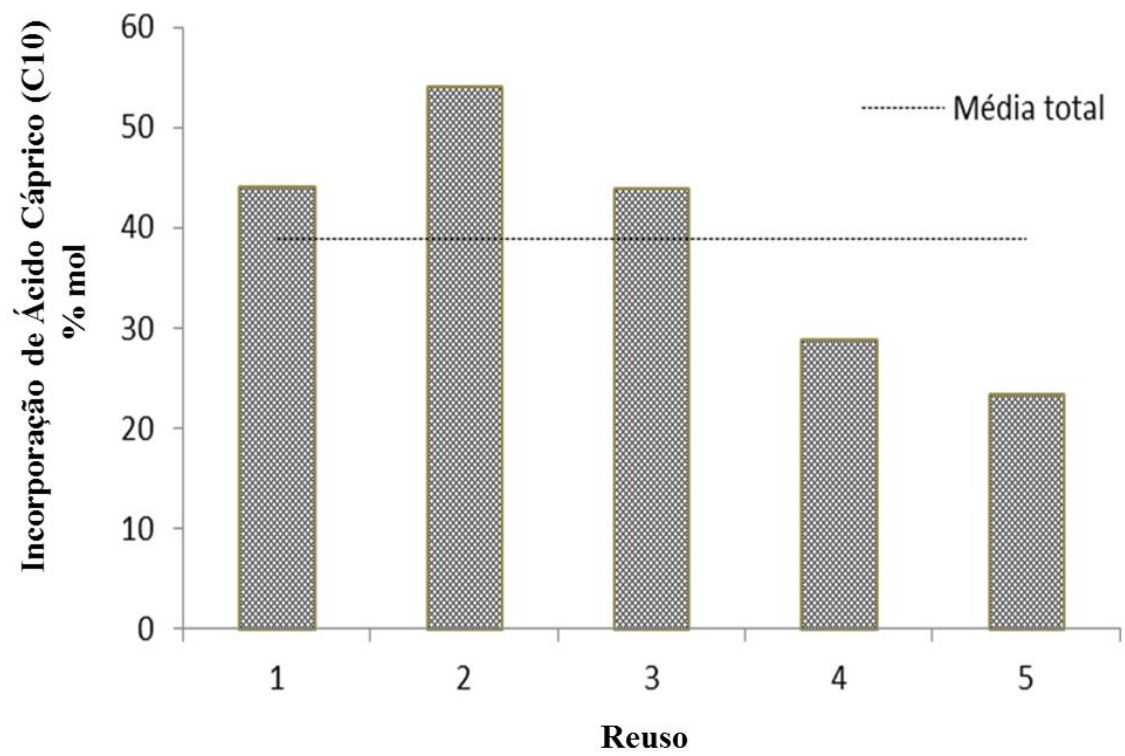

Como nota-se na figura 2 acima, o GI durante o reuso variou de 23,38 a 54,00 \% mol. Coletando todos os volumes dos reusos e analisando o grau de incorporação, obteve-se uma média de 38,80 \%mol. Tais valores são satisfatórios e mostram que o processo de imobilização foi eficiente, uma vez que um dos propósitos ao se imobilizar uma enzima é possibilitar seu reuso mantendo-se sua atividade catalítica, pois dessa maneira, os custos operacionais podem ser minimizados, viabilizando o bioprocesso (SHELDON; PELT, 2013). Neste trabalho, pode-se observar que a lipase imobilizada em pó de sabugo de milho apresentou relevante estabilidade operacional, justificando a necessidade de realização do processo de imobilização empregado. 


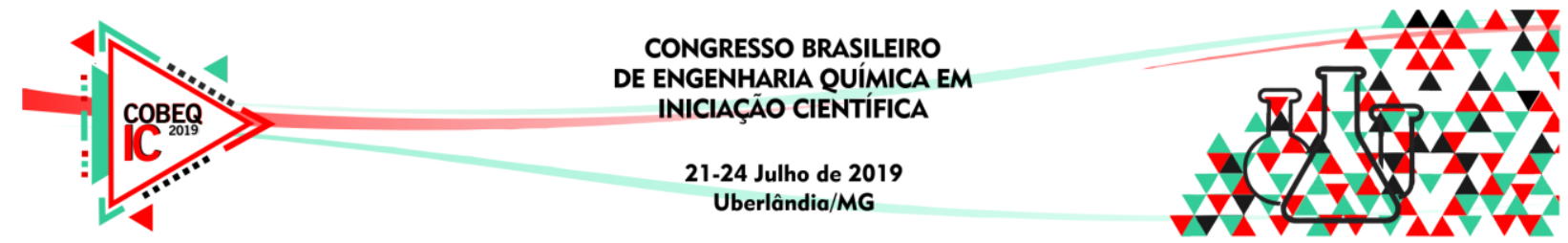

\section{CONCLUSÃO}

Pode-se concluir que o emprego de lipase imobilizada em pó de sabugo de milho na síntese de lipídeos estruturados mostrou-se muito relevante, indicando que tal suporte de baixo custo é um promissor material para imobilização de enzimas. Além disso, a síntese de um triglicerídeo com propriedades nutracêuticas mostrou-se eficiente e indica um promissor campo de estudos na área de bioprocessos e enzimologia.

\section{AGRADECIMENTOS}

À Fundação de Amparo à Pesquisa do Estado de São Paulo, FAPESP (Processos 2018/039325 e 2017/11482-7).

\section{REFERÊNCIAS}

ASHOUR, A.; AMER, M.; MARZOUK, A.; SHIMIZU, K.; KONDO,R.; EL-SHARKWY, S. Corncobs as a Potencial Source of Funcional Chemicals. Molecules, v.18, n.11, Nov. 2013

BASSAN, C. J.; SOUZA, B. M. T.; PEIXOTO, G.; CRUZ, P. Z. C.; GALÁN, M. P, J.; VAZ, S. B .A.; GARRIDO, S.S.; FILICE, M.; MONTI, R. Immobilization of trypsin in lignocellulosic waste material to produce peptides with bioactive potencial from whey protein. Materials, v. 9, n. 5, 2016.

BRÍGIDA, A. I. S. Imobilização de lipases utilizando fibra de coco verde como suporte para aplicações industriais. 2010. 220 f. Tese (Doutorado em ciências) - Escola de Química, Universidade Federal do Rio de Janeiro, Rio de Janeiro, 2010.

CABRAL, M.S.; AIRES-BARROS, M. R.; GAMA, M. Engenharia enzimática. Lisboa: Lidel, 2003.

CASAS-GODOY, L.; MARTY, A.; SANDOVAL, G.; FERREIRA - DIAS, S. Optimization of medium chain length fatty acid incorporation into olive oil catalyzed by immobilized Lip2 from Yarrowia lipolytica. Bioch. Eng. Journal. v. 77, p. 20 - 27, 2013.

CASTRO, H.F.D.; MENDES, A.A.; SANTOS, J.C.D.; AGUIAR, C.L.D. Modification of oils and fats by biotransformation. Quimica Nova, v. 27, n. 1, p. 146-156, 2004.

NARWAL, S.K.; GUPTA, R. Biodiesel production by transesterification using immobilized lipase. Biotech. Letters, v. 35, p. 479-490, 2013.

NUNES, P. A.; P., PIRES-CABRAL; GUILLEN, M.; VALERO, F.; LUNA, D.; FERREIRA-DIAS; S. Production of MLM-type structured lipids catalyzed by immobilized heterologous Rhizopus oryzae lipase. JAOCS, v. 88, p.473-480, 2011-b.

NUNES, P.A.; PIRES-CABRAL, P.; GUILLÉN, M.; VALERO, F.; FERREIRA-DIAS, S. Optimized production of MLM triacylglycerols catalyzed by immobilized heterologous Rhizopus oryzae lipase. JAOCS, v. 89, n. 7, p. 1287-1295, 2012.

PAULA, A. V. Reestruturação da gordura de leite por interesterificação enzimática empregando lipase imobilizada: otimização das condições reacionais e operacionais. 2011. 212 f. Tese (Doutorado em Ciências) - Escola de Engenharia de Lorena, Universidade de São Paulo, Lorena/SP, 2012.

SHELDON, R. A.; PELT, S. Enzyme immobilization in biocatalysis: why, what and how. Chem. Society Reviews, v. 42, n. 15, Mar. 2013.

SILVA, R.C.; COTTING, L.N.; POLTRONIERI, T.P.; BALCÃO, V.M.; ALMEIDA, D.B.; GONÇALVES, L.A.G.; GRIMALDI, R.; GIOLLI, L.A. The effects of enzymatic interesterification on the physical - chemical, properties of blends of lard and soybean oil. LWT - Food Science and Technology, v. 42, n. 7, p. 1275-1282, 2009. 